\title{
Prevalence and Risk Factors of Osteoporosis Among Jordanian Postmenopausal Women Attending the National Center for Diabetes, Endocrinology and Genetics in Jordan
}

\author{
Dana Hyassat, Taghreed Alyan, Hashem Jaddou, and Kamel M. Ajlouni, **
}

\begin{abstract}
To assess the prevalence of osteoporosis and osteopenia among Jordanian postmenopausal women attending the National Center for Diabetes, Endocrinology, and Genetics (NCDEG), and to determine the potential associated risk factors. A cross-sectional study was conducted at (NCDEG) in Amman, Jordan. A total of 1079 Jordanian postmenopausal women aged between 45 and 84 years were included in this study that was conducted during the period between April 2013 and December 2014. All patients underwent bone mineral density measurement through dual-energy X-ray absorptiometry (DEXA) scan. DEXA scan was interpreted in terms of T score as per World Health Organization guidelines. The overall prevalence of osteoporosis and osteopenia was 37.5\% and $44.6 \%$, respectively. The maximum prevalence of osteoporosis was observed at the lumbar spine (32.4\%) followed by the left femoral neck (14.4\%), while the maximum prevalence of osteopenia was observed at the left femoral neck (56.1\%) followed by the lumbar spine (41.3\%). Patients with longer menopausal duration, normal or overweight body mass index, high parity, physical inactivity, positive family history of osteoporosis, inadequate sun exposure, high daily caffeine intake, low daily calcium intake, and delay in the age of menarche were all positively associated with osteoporosis. On the other hand, women with type 2 diabetes mellitus had lower risk of osteoporosis. There is a high prevalence of osteoporosis and osteopenia among Jordanian postmenopausal women. Necessary steps are needed for more public education and a wider dissemination of information about osteoporosis and its prevention.
\end{abstract}

Keywords: Jordan; osteoporosis; prevalence; risk factors; type 2 diabetes mellitus

\section{Introduction}

Osteoporosis causes more than 8.9 million fractures annually worldwide, resulting in an osteoporotic fracture every 3 seconds. ${ }^{1}$

Women are at a significantly higher risk for osteoporosis, which is estimated to affect around 200 million women worldwide. ${ }^{2}$ In Jordan, Shilbayeh ${ }^{3}$ found that the overall rate of osteoporosis was $30 \%$ among Jordanian women irrespective of menopausal status and $43.3 \%$ among postmenopausal women. In addition, El-Heis et al. reported that the prevalence of osteoporosis among a sample of Jordanian women referred for investigation of osteoporosis was $13.5 \%$ with current age; age at menarche, diabetes mellitus, hypertension, and renal problems were all significantly associated with an increased risk of osteoporosis. ${ }^{4}$ One half of all postmenopausal women will experience an osteoporosis-related fracture during their lifetime, $25 \%$ of these women will develop a vertebral deformity, and $15 \%$ will experience a hip fracture. ${ }^{5}$ Nearly $75 \%$ of all hip fractures occur in

\footnotetext{
${ }^{1}$ Department of Endocrinology, The National Center (Institute) for Diabetes, Endocrinology and Genetics (NCDEG)/The University of Jordan, Amman, Jordan. ${ }^{2}$ Department of Epidemiology and Public Health, The Jordan University of Science and Technology (JUST), Irbid, Jordan.

*Address correspondence to: Kamel M. Ajlouni, MD, FACP, FACE, The National Center for Diabetes, Endocrinology and Genetics, PO Box 13165, Amman 11942, Jordan, E-mail: ajlouni@ju.edu.jo
} 
women and are invariably associated with chronic pain, disability, reduced mobility, increasing dependence, and future fractures risk. ${ }^{6}$ Moreover, osteoporosis-related hip fracture is associated with increased mortality. During the first year following a hip fracture, the mortality rate reaches $20 \%{ }^{7}$

Risk factors associated with osteoporosis include age, female sex, ethnicity, family history of osteoporosis, smoking, vitamin D deficiency, low calcium and high caffeine intake, immobilization, increased age at menarche, early menopause, and underweight. ${ }^{8}$

The association between diabetes and osteoporosis is complex. Type 1 diabetes mellitus (T1DM) is characterized by low bone mineral density (BMD) due to low circulating levels of IGF-1 and insulin, and this usually occurs in young children before peak bone mass attainment. While type 2 diabetes mellitus (T2DM) is common in adults who have already attained peak bone mass, the effect of T2DM on BMD is controversial; it might have increased, decreased, or stayed normal. ${ }^{9,10}$

\section{Aim of the Study}

To assess the prevalence of osteoporosis and osteopenia among Jordanian postmenopausal women attending the National Center for Diabetes, Endocrinology, and Genetics (NCDEG), and to determine the potential associated risk factors.

\section{Materials and Methods}

Sampling and data collection

A cross-sectional study was carried out between April 2013 and December 2014 at the NCDEG in Amman, Jordan. All Jordanian women aged $\geq 45$ years, of menopausal duration of more than 1 year, and who had received BMD by dual-energy X-ray absorptiometry (DEXA) at our center during the study period were eligible to be included in the study.

Patients with T1DM, malignancy, hyperthyroidism, uncontrolled hypothyroidism, primary or secondary hyperparathyroidism, Cushing syndrome, cirrhosis, systemic lupus erythematosus, rheumatoid arthritis, renal impairment, epilepsy, and premature menopause $(<45$ years old), or patients on one or more of the following medications: thiazolidinedione, heparin, warfarin, vitamin $\mathrm{K}$, thiazide diuretics, anticonvulsants, cancer chemotherapy, $\mathrm{GnRH}$ (gonadotropin releasing hormone agonists), estrogen, barbiturates, methotrexate or glucocorticoids, were excluded from the study.

The data sources used were the patient's medical record and a structured interview questionnaire that was carried over the phone. The medical file was used to gather information on current age at BMD measurement, marital status, educational level, duration of menopause, age at menopause and menarche onset, parity, number of pregnancies and abortions, years of menstruation, breast feeding, diabetes status and its duration, hypertension status and use of statin or vitamin D3 supplementation, weight, and height.

The phone interview was used to gather information on lifestyle factors such as daily calcium intake, physical activity, lifetime daily caffeine consumption, sun exposure, smoking habit, immobilization status, family history of osteoporosis or fragility fracture, and history of pervious personal fragility fracture. Any other missing data from the medical file were completed through the phone interview.

\section{Ethical considerations}

The study protocol was approved by the ethics committee at the NCDEG. Through the phone calls, verbal consents were taken from the patients, and they were assured of confidentiality of data and to be used only for scientific research.

\section{Definitions of the study variables}

Measurements and laboratory analysis. Body mass index (BMI) was expressed as the quotient between weight $(\mathrm{kg})$ and height squared $\left(\mathrm{m}^{2}\right)$. Patients were classified according to BMI following the recommendation of the World Health Organization (WHO) as adopted by the American Diabetes Association (ADA). ${ }^{11}$ Smoking was classified into three categories according to WHO guidelines 1998; current smoker: a person who smokes cigarettes daily or occasionally; past-smoker: a person who formerly was a daily or occasional smoker, but currently does not smoke at all; and nonsmoker: a person who has never smoked before or has smoked very little in the past. ${ }^{12}$

Physical activity was measured as "the leisure time of any kind of moderate-intensity aerobic physical activity for a minimum of 30 minutes on five days each week."13

Immobilization was defined as "being confined to bed for a continuous period $>2$ months." ${ }^{14}$

Pre-diabetes and diabetes was diagnosed according to the ADA 2014. Moreover, diabetes was considered to be controlled if the patient had $\mathrm{HbA} 1 \mathrm{c}<7.0 \%$, fairly controlled if the patient had HbAlc between $7 \%$ and $7.9 \%$, and uncontrolled if $\mathrm{HbAlc} \geq 8 \%$.

Sun exposure was defined in adults as "exposure of the hands, face, and arms to the sun daily for 10-15 minutes per day (uncovered and without sun screen)."15 
Lifetime daily caffeine intake was estimated as the average daily intake of coffee, tea, caffeinated soft drinks, chocolate, and ice coffee. Coffee includes several types of instant, brewed, and Turkish coffee. The caffeine content was based on figures from the International Food Information Council Foundation Review ${ }^{16}$ and was estimated in milligrams per day, each cup $(8 \mathrm{oz}$. of brewed coffee contains $85 \mathrm{mg}$ caffeine), (8 oz. of instant coffee contains $75 \mathrm{mg}$ caffeine), ( $8 \mathrm{oz}$. of brewed tea contains $40 \mathrm{mg}$ caffeine), (12 oz. of cola contains $40 \mathrm{mg}$ caffeine). The mean caffeine concentration per cup of Turkish coffee $(40 \mathrm{~mL})$ is $165 \mathrm{mg} .{ }^{17}$ Lifetime daily caffeine intake was coded into two different groups: 0 , low caffeine intake $(\leq 300 \mathrm{mg} /$ day), and 1 , high caffeine intake $(>300 \mathrm{mg} /$ day), at data analysis. ${ }^{18}$

Duration of menopause was calculated by subtracting age at menopause from current age at BMD measurement. Years of menstruation was calculated as the difference in years between age at menopause and age at menarche.

$\mathrm{BMD}$ was measured at the lumbar spine L1-L4 (anterior-posterior projection) and left femoral neck using DEXA (Hologic Discovery A Scanner), and expressed as $\mathrm{g} / \mathrm{cm}^{2}$. T-score value was only considered for analysis as recommended by the WHO diagnostic classification, ${ }^{19}$ which classified the patients into three categories: normal BMD defined as (T-score at -1.0 and above), osteopenia (low bone mass) defined as (T-score between -1.0 and -2.5 ), while osteoporosis was defined as (T-score at or below -2.5 ).

Serum vitamin D3 concentrations were determined using radioimmunoassay (BIOSOURCE Europe S.A., Nivelles, Belgium) and was classified as follows: vitamin D deficiency $(>20 \mathrm{ng} / \mathrm{mL})$, vitamin D insufficiency (20$29 \mathrm{ng} / \mathrm{mL})$, and vitamin D sufficient $(\geq 30 \mathrm{ng} / \mathrm{mL}){ }^{20}$

\section{Statistical analysis}

Data were analyzed using the Statistical Program for Social Sciences (SPSS) version 20.0. Data were examined for data entry errors and outlying values; any error was corrected as appropriate. The overall prevalence of osteoporosis was calculated. The bivariate association between osteoporosis and a number of variables was assessed for statistical significance using the Chi-square test and $t$-test. Multivariate logistic regression was used to assess the independent variables of the disease status after adjusting for potential confounders, using adjusted odds ratios (OR) and $95 \%$ confidence intervals. $p$ Value of $<0.05$ was considered statistically significant.

\section{Results}

Participant characteristics

This study included 1079 Jordanian postmenopausal women, aged $45-84$ years with a mean age (standard deviation) of 61.1 (7.2) years.

The sociodemographic, reproductive, and clinical characteristics, family history of osteoporosis and fragility fractures, pervious personal fragility fractures, lifestyle, and laboratory characteristics of the study population are represented in Table 1. More than one-half $(55 \%)$ of the sample was 60 years of age or more, $62 \%$ had their menopause at the age of 50 years or less, $49 \%$ had a menopausal duration of 11 years or more, and $26 \%$ had a menopausal duration of 5 years or less.

Ninety percent of the participants were married, $8 \%$ were single, and $15 \%$ were current smokers. More than half of the participants had an educational attainment of more than high school, $28 \%$ of them had less than high school education, $61 \%$ were obese, and $30 \%$ were overweight. About one-half of the participants were diabetic, $37 \%$ were pre-diabetic, and $13 \%$ had no diabetes. Of those who had diabetes, $40 \%$ of them had duration of diabetes of 10 years or more and $35 \%$ had diabetes duration of less than 5 years. Forty-nine percent of the diabetic participants had $\mathrm{HbAlc}$ of less than $7 \%$, while $51 \%$ had $\mathrm{HbAlc}$ more than or equal to $7 \%$. Sixty-four percent of the patients were hypertensive, $68 \%$ were on statin treatment for dyslipidemia, and $89 \%$ were taking vitamin D3 supplementation. Thirty-eight percent of the population had a parity of six children or more and $20 \%$ had two children or less. Thirty-nine percent of the women reported a history of one to two abortions and 50\% had no history of abortion. Sixty percent of our population was physically inactive, $53 \%$ had inadequate sun exposure, $52 \%$ of them had high daily caffeine intake more than $300 \mathrm{mg} /$ day, and $31 \%$ had low daily calcium intake of less than $600 \mathrm{mg} /$ day. Thirty-two percent of the study population had reported a positive family history of osteoporosis, 3\% had a history of immobilization, $24 \%$ had a positive family history of fragility fracture, and $19 \%$ had a personal history of previous fragility fracture. More than one-third (38\%) of our sample had either vitamin D3 deficiency or insufficiency and $34 \%$ of our population had high parathyroid hormone of more than $55 \mathrm{pg} / \mathrm{mL}$.

\section{Prevalence of osteoporosis}

The overall prevalence of osteoporosis in the study population (1079) was $37.5 \%(n=405)$, and $44.6 \%(n=481)$ were diagnosed with osteopenia. The maximum prevalence of osteoporosis at the lumbar spine was observed 
Table 1. Frequency Distribution of the Study Sample by Certain Sociodemographic, Reproductive, Clinical, Lifestyle, and Laboratory Characteristics, and Health (Family History of Osteoporosis, Family History

of Fragility Fracture, and Personal of Previous Fragility Fracture) Variables $(n=1079)$

\begin{tabular}{lll}
\hline Variable & $n$ & $\%$
\end{tabular}

Current age at BMD (years)

$<60$

$\geq 60$

Marital status

Single

Married

Divorced or widowed

488

591

86

974

19

Education

$<$ High school

High school

$>$ High school

BMI $\left(\mathrm{kg} / \mathrm{m}^{2}\right)$

Normal

Overweight

Obese

Smoking

Never smoke

Current

Physical activity

No

Yes

Sun exposure

No

Yes

Lifetime daily caffeine ( $\mathrm{mg} /$ day)

$\leq 300$

$>300$

Calcium intake (mg/day)

$<600$

600-1000

$>1000$

Diabetic status

No

Pre-DM

DM

Duration of diabetes (years)

$<5$

5-9

$\geq 10$

Hypertension

No

Yes

Use of statin

No

Yes

Use of vitamin D3

No

Yes

Immobilization

No

Yes

$\mathrm{HbA1c}$ for diabetic

Controlled $(<7 \%)$

Fairly controlled $(7-7.9 \%)$

Un controlled $(\geq 8 \%)$
Table 1. (Continued)

\begin{tabular}{|c|c|c|}
\hline Variable & $n$ & $\%$ \\
\hline \multicolumn{3}{|c|}{ Parathyroid hormone $(\mathrm{pg} / \mathrm{mL})$} \\
\hline$\leq 55$ & 512 & 66.3 \\
\hline$>55$ & 260 & 33.7 \\
\hline \multicolumn{3}{|l|}{ Vitamin D3 level (ng/mL) } \\
\hline Normal $(\geq 30)$ & 624 & 61.8 \\
\hline Insufficiency (20-29) & 183 & 18.1 \\
\hline Deficiency $(<20)$ & 203 & 20.1 \\
\hline \multicolumn{3}{|l|}{ Age at menopause (years) } \\
\hline$\leq 50$ & 667 & 61.8 \\
\hline$>50$ & 412 & 38.2 \\
\hline \multicolumn{3}{|c|}{ Menopausal duration at time of performing DEXA (years) } \\
\hline$\leq 5$ & 283 & 26.2 \\
\hline $6-10$ & 268 & 24.8 \\
\hline$\geq 11$ & 528 & 48.9 \\
\hline Age at menarche (years) & \multirow{2}{*}{\multicolumn{2}{|c|}{$\begin{array}{l}\text { mean } \pm S D=13.71 \pm 1.58 \\
\text { mean } \pm S D=36.12 \pm 3.58\end{array}$}} \\
\hline Menstruation years (years) & & \\
\hline \multicolumn{3}{|l|}{ Parity } \\
\hline$\leq 2$ & 210 & 19.5 \\
\hline $3-5$ & 464 & 43 \\
\hline$\geq 6$ & 405 & 37.5 \\
\hline \multicolumn{3}{|l|}{ Abortion } \\
\hline None & 538 & 49.9 \\
\hline $1-2$ & 418 & 38.7 \\
\hline$\geq 3$ & 123 & 11.4 \\
\hline \multicolumn{3}{|l|}{ Ever breast feed } \\
\hline No & 225 & 20.9 \\
\hline Yes & 854 & 79.1 \\
\hline \multicolumn{3}{|c|}{ Family history of osteoporosis } \\
\hline No & 739 & 68.5 \\
\hline Yes & 340 & 31.5 \\
\hline \multicolumn{3}{|c|}{ Family history of fragility fracture } \\
\hline No & 817 & 75.7 \\
\hline Yes & 262 & 24.3 \\
\hline \multicolumn{3}{|c|}{ Personal of previous fragility fracture } \\
\hline No & 874 & 81.0 \\
\hline Yes & 205 & 19.0 \\
\hline
\end{tabular}

$B M D$, bone mineral density; $B M I$, body mass index; DEXA, dual-energy X-ray absorptiometry; DM, diabetes mellitus; SD, standard deviation.

in $32.4 \%$ of the participants, followed by the left femoral neck (14.4\%), while the prevalence of osteopenia was observed more at the left femoral neck (56.1\%) followed by the lumbar spine (41.3\%; Table 2 ).

Chi-square distribution was used to examine the independent distribution of osteoporosis by certain study variables. As indicated in Table 3, older age group, physically inactive, less sun exposed, participants with high parathyroid level, more caffeine drinkers, those with family history of osteoporosis/fragility fracture, and those with previous personal fragility fracture were more likely to have osteoporosis than their counterparts ( $p$-value $0.000,0.000,0.000,0.038,0.015,0.000$, $0.001)$, respectively. Table 3 also indicated that marital status, BMI, calcium intake, diabetes status, duration of diabetes, menopausal duration, and parity were significantly positively associated with osteoporosis ( $p$ values 
Table 2. Prevalence of Osteoporosis and Osteopenia Among Jordanian Postmenopausal Women (No. 1079)

\begin{tabular}{lccc}
\hline & Normal (\%) & Osteopenia (\%) & Osteoporosis (\%) \\
\hline Total & 17.89 & 44.58 & 37.53 \\
Lumbar spine & 26.2 & 41.3 & 32.4 \\
Left femoral neck & 29.6 & 56.1 & 14.4 \\
\hline
\end{tabular}

Table 3. Chi-Square Distribution and Level of Significance of Osteoporosis by Certain Sociodemographic and Health Variables $(n=1079)$

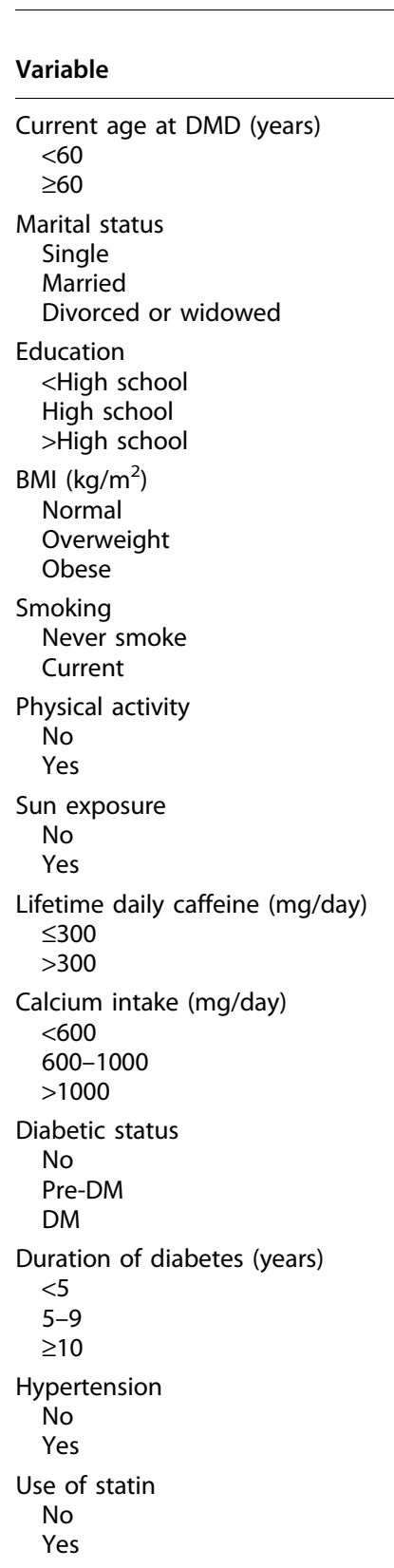

Table 3. (Continued)

\begin{tabular}{|c|c|c|c|}
\hline Variable & $\begin{array}{l}\text { Normal } \\
\text { no. (\%) }\end{array}$ & $\begin{array}{l}\text { Osteoporosis } \\
\text { no. (\%) }\end{array}$ & $p$ \\
\hline Use of vitamin D3 & & & 0.325 \\
\hline No & $67(58.3)$ & $48(41.7)$ & \\
\hline Yes & $607(63)$ & $357(37)$ & \\
\hline Immobilization & & & 0.556 \\
\hline No & $658(62.6)$ & $39.3(37.4)$ & \\
\hline Yes & $16(57.1)$ & $12(42.9)$ & \\
\hline HbA1c for diabetic & & & 0.403 \\
\hline Controlled $(<7 \%)$ & $173(66.5)$ & 87 (33.5) & \\
\hline Fairly controlled (7-7.9\%) & $98(70)$ & $42(30)$ & \\
\hline Uncontrolled $(\geq 8 \%)$ & $79(62.2)$ & $48(37.8)$ & \\
\hline Parathyroid hormone $(\mathrm{pg} / \mathrm{mL})$ & & & 0.038 \\
\hline$\leq 55$ & $325(63.5)$ & $187(36.5)$ & \\
\hline$>55$ & $145(55.8)$ & $115(44.2)$ & \\
\hline Vitamin D3 level (ng/mL) & & & 0.279 \\
\hline Normal $(\geq 30)$ & $377(60.4)$ & 247 (39.6) & \\
\hline Insufficiency (20-29) & $116(63.4)$ & $67(36.6)$ & \\
\hline Deficiency $(<20)$ & $135(66.5)$ & $68(33.5)$ & \\
\hline Age at menopause (years) & & & 0.390 \\
\hline$\leq 50$ & $410(61.5)$ & $257(38.5)$ & \\
\hline$>50$ & $264(64.1)$ & $148(35.9)$ & \\
\hline $\begin{array}{l}\text { Menopausal duration at time } \\
\text { of performing DEXA (years) }\end{array}$ & & & 0.000 \\
\hline$\leq 5$ & $211(74.6)$ & $72(25.4)$ & \\
\hline $6-10$ & $166(61.9)$ & $102(38.1)$ & \\
\hline$\geq 11$ & $279(56.2)$ & $231(43.8)$ & \\
\hline Parity & & & 0.052 \\
\hline$\leq 2$ & $125(59.5)$ & $85(40.5)$ & \\
\hline $3-5$ & $309(66.6)$ & $155(33.4)$ & \\
\hline$\geq 6$ & $240(59.3)$ & $165(40.7)$ & \\
\hline Abortion & & & 0.752 \\
\hline None & $342(63.6)$ & $196(36.4)$ & \\
\hline $1-2$ & $256(61.2)$ & $162(38.8)$ & \\
\hline$\geq 3$ & $76(61.8)$ & $47(38.2)$ & \\
\hline Ever breast feed & & & 0.186 \\
\hline No & $132(58.7)$ & $93(41.3)$ & \\
\hline Yes & $542(63.5)$ & $312(36.5)$ & \\
\hline Family history of osteoporosis & & & 0.000 \\
\hline No & $492(66.6)$ & $247(33.4)$ & \\
\hline Yes & $182(53.5)$ & $158(46.5)$ & \\
\hline Family history of fragility fracture & & & 0.000 \\
\hline No & $538(65.9)$ & $279(34.1)$ & \\
\hline Yes & $136(51.9)$ & $126(48.1)$ & \\
\hline Previous personal fragility fracture & & & 0.001 \\
\hline No & $567(64.9)$ & $307(35.1)$ & \\
\hline Yes & $107(52.2)$ & $98(47.8)$ & \\
\hline
\end{tabular}

$0.002,0.000,0.013,0.003,0.045,0.000,0.052)$, respectively. No significant association was found between osteoporosis and each of educational level, age of menopause, number of abortions, breast feeding, hypertension, use of statin or vitamin D3 supplementation, immobilization, smoking status, $\mathrm{HbA1c}$ level for diabetic participants, vitamin D3 level, calcium, phosphorus, albumin, alkaline phosphatase, and creatinine levels.

$T$-test indicated that the mean age at menarche among osteoporotic patients was significantly higher than the nonosteoporotic group ( $p$-value 0.004$)$. However, no 
Table 4. T-test Between Osteoporosis and Normal Groups Among the Study Participants $(n=1079)$

\begin{tabular}{llccc}
\hline Variable & Group & Mean & $\begin{array}{c}\text { Standard } \\
\text { deviation }\end{array}$ & $\boldsymbol{p}$ \\
\hline Age at menarche (years) & Normal & 13.60 & 1.55 & 0.004 \\
& Osteoporosis & 13.89 & 1.62 & \\
Years of menstruation & Normal & 36.22 & 3.62 & 0.232 \\
& Osteoporosis & 35.95 & 3.51 & \\
& & &
\end{tabular}

significant difference was found between the two groups in the mean years of menstruation, Table 4 .

Multivariate analysis

Multiple logistic regression analysis was performed to examine the net effect of certain variables on osteoporosis after controlling for the effect of other variables in the model.

As shown in Table 5, the variables of menopausal duration, BMI, parity, diabetes status, family history of osteoporosis, physical activity, sun exposure, lifetime daily caffeine intake, daily calcium intake, and age at menarche were significant to the model. Current age at time of performing (DEXA), smoking, and vitamin D3 level were not significant to the model.

Patients with menopausal duration between $6-10$ years and more than 11 years were 1.9 and 2.3 times ( $p$ values $0.003,0.002)$, respectively, more likely to have osteoporosis compared to postmenopausal women who had menopausal duration $\leq 5$ years.

The likelihood to develop osteoporosis among postmenopausal women with normal BMI and overweight were 3.1 and 2.6 times ( $p$ values $0.000,0.000$ ), respectively, compared to obese postmenopausal women. Parity of $\geq 6$ children increased the risk of having osteoporosis by 1.6 times in comparison with a parity of $\leq 2$ children ( $p$-value 0.027).

Being nondiabetic or pre-diabetic increased the risk of having osteoporosis by 2.1 and 1.7 times ( $p$ values 0.001 , 0.001 ), respectively, in comparison with diabetic patients. Having a positive family history of osteoporosis, physical inactivity, and inadequate sun exposure was associated with an increased risk of osteoporosis; OR were 1.8, 1.5, and 1.4 and $p$ values were $0.000,0.008$, and 0.023 , respectively. Participants with daily caffeine intake of more than $300 \mathrm{mg} /$ day and calcium intake of less than $600 \mathrm{mg} /$ day were more likely to develop osteoporosis than their counterparts; OR were 1.5 and 1.6 and $p$ values were 0.005 and 0.018 , respectively. The risk of osteoporosis increased by $10 \%$ for each 1 year delay in the age of menarche, OR 1.1 and $p$-value 0.013 .

\begin{tabular}{|c|c|c|}
\hline Variable & OR & $p$ \\
\hline \multicolumn{3}{|c|}{ Menopausal duration (years) } \\
\hline$\leq 5$ & 1 & \\
\hline $6-10$ & 1.9 & 0.003 \\
\hline$\geq 11$ & 2.3 & 0.002 \\
\hline \multicolumn{3}{|l|}{ BMI $\left(\mathrm{kg} / \mathrm{m}^{2}\right)$} \\
\hline Normal & 3.1 & 0.000 \\
\hline Overweight & 2.6 & 0.000 \\
\hline Obese & 1 & \\
\hline \multicolumn{3}{|l|}{ Parity } \\
\hline$\leq 2$ & 1 & \\
\hline $3-5$ & 0.864 & 0.460 \\
\hline$\geq 6$ & 1.6 & 0.027 \\
\hline \multicolumn{3}{|l|}{ Diabetic status } \\
\hline No & 2.1 & 0.001 \\
\hline Pre-diabetic & 1.7 & 0.001 \\
\hline DM & 1 & \\
\hline \multicolumn{3}{|c|}{ Family history of osteoporosis } \\
\hline No & 1 & \\
\hline Yes & 1.8 & 0.000 \\
\hline \multicolumn{3}{|l|}{ Physical activity } \\
\hline No & 1.4 & 0.014 \\
\hline Yes & 1 & \\
\hline \multicolumn{3}{|l|}{ Sun exposure } \\
\hline No & 1.4 & 0.023 \\
\hline Yes & 1 & \\
\hline \multicolumn{3}{|c|}{ Lifetime daily caffeine intake (mg/day) } \\
\hline$\leq 300$ & 1 & \\
\hline$>300$ & 1.6 & 0.005 \\
\hline Age at menarche & 1.1 & 0.013 \\
\hline \multicolumn{3}{|l|}{ Calcium intake (mg/day) } \\
\hline$<600$ & 1.6 & 0.018 \\
\hline $600-1000$ & 1.3 & 0.494 \\
\hline$>1000$ & 1 & \\
\hline \multicolumn{3}{|l|}{ Smoking } \\
\hline No & 1 & \\
\hline Yes & 1.2 & 0.647 (NS) \\
\hline \multicolumn{3}{|c|}{ Current age (years) at BMD } \\
\hline$<60$ & 1 & \\
\hline$\geq 60$ & 1.4 & 0.114 (NS) \\
\hline \multicolumn{3}{|l|}{ Duration of DM (years) } \\
\hline$<5$ & 0.74 & 0.23 (NS) \\
\hline $5-10$ & 0.99 & 0.96 (NS) \\
\hline$>10$ & 1 & \\
\hline \multicolumn{3}{|l|}{ Vitamin D3 levels } \\
\hline Normal $(\geq 30)$ & 1 & \\
\hline Insufficiency (20-29) & 1.23 & 0.282 (NS) \\
\hline Deficiency $(<20)$ & 1.19 & 0.453 (NS) \\
\hline
\end{tabular}

Using multiple logistic regression analysis. NS, not significant; OR, odds ratio.

However, there was no association between osteoporosis and each of smoking, current age at time of performing DEXA, and vitamin D3 level.

\section{Discussion}

In this study, the prevalence of osteoporosis among Jordanian postmenopausal women attending the NCDEG 
was $37.5 \%$. This finding was higher than the $16.2 \%$ prevalence rate reported in Turkey, ${ }^{21}$ comparable to the $37.8 \%$ in India, ${ }^{22}$ but lower than the $44.1 \%$ prevalence rate reported in Saudi Arabia. ${ }^{23}$ This inconsistency in the findings is perhaps related to differences in study design, diagnostic technique used, bone scan site chosen, lifestyle practice, and selection of patients.

Our data showed that nondiabetics or pre-diabetics were at a higher risk of developing osteoporosis than type 2 diabetic patients. This finding was consistent with the findings reported in several studies, ${ }^{24-26}$ but not in other studies. ${ }^{27,28}$

This study confirmed that the years that had elapsed since menopause was an important factor for predicting osteoporosis even after adjusting for other variables. This finding was in agreement with that reported in research literature. $^{21,29,30}$

Our study showed an association between the increase in age at menarche and risk of developing osteoporosis. Early menarche may have a protective effect on the development of osteoporosis since it is associated with higher circulating estrogen during and after menarche. Ito et al. and Parker et al. also found that there was a positive correlation of early menarche with high BMD. ${ }^{31,32}$ However, our result was inconsistent with other studies, ${ }^{33-35}$ which found no association between age at menarche and $\mathrm{BMD}$, or fracture risk.

Consistent with the findings from other studies, ${ }^{36,37}$ our data indicated that high parity was a risk factor for osteoporosis. On the other hand, Sadat-Ali et al. concluded that increased parity protects postmenopausal women from osteoporosis. ${ }^{23}$

Our data showed that obesity had a protective effect against osteoporosis and the effect of higher BMI may compensate for the negative influence of hypoestrogenic state on BMD during menopause. Several studies also supported this finding and suggested that higher body weight may underline both high bone density and lower incidence of fracture. ${ }^{38,39}$ Many explanations had been suggested to explain such correlation, one of them is that larger body mass forces a greater mechanical loading on bone, thus the bone mass increases to accommodate this load. In addition, adipocytes are important sources of estrogen production in postmenopausal women and estrogen is known to inhibit bone resorption by osteoclasts. Inconsistent with our finding, Zhao et al. found that an increasing fat mass might not have a beneficial effect on bone mass. ${ }^{40}$

In our study, postmenopausal women with a daily caffeine intake of $>300 \mathrm{mg} /$ day were at greater risk of devel- oping osteoporosis. Consistent with our finding, Rapuri et al. had also found that the intake of caffeine in amounts $>300 \mathrm{mg} /$ day accelerates bone loss at the spine in elderly postmenopausal women. ${ }^{18}$ On the other hand, $\mathrm{Ng}$ et al. showed a clinically protective effect of coffee consumption on periodontal bone loss. ${ }^{41}$ Several studies had demonstrated that caffeine acts directly on osteoblasts and osteocytes, disturbing the process of differentiation, multiplication, mineralization, and bone matrix production, leading to apoptosis of these cells. ${ }^{42-45}$ In addition, caffeine may increase the differentiation of osteoclasts, resulting in greater loss of calcium in urine. ${ }^{46}$ All these mechanisms may contribute to the decrease in bone density caused by high caffeine consumption.

It is well known that adequate calcium intake is an important factor for the maintenance of bone health during growing phase, ${ }^{47,48}$ as well as the preservation of BMD in elderly individuals. ${ }^{49,50}$ When calcium levels decrease, there is a fast compensatory increase in parathyroid hormone that stimulates osteoclast-mediated bone resorption. ${ }^{51,52}$ One of the important findings in our study was the association between low calcium intake $(<600 \mathrm{mg} /$ day) and osteoporosis. In agreement with our finding, Ensrud et al. had reported that in elderly women, low fractional calcium absorption in the setting of low calcium intake increases the risk for hip fracture. ${ }^{53}$

Postmenopausal patients who lack adequate sun exposure were at a higher risk for developing osteoporosis in our study. However, our study failed to demonstrate the effect of vitamin D deficiency on osteoporosis since the vast majority of our patients were on vitamin $\mathrm{D}$ supplementation. In contrast with our findings, Gaugris et al. and Mezquita-Raya et al. found that an inadequate vitamin $\mathrm{D}$ level in postmenopausal women was a common risk factor for osteoporosis. ${ }^{54,55}$

Our study showed that an inadequate physical activity was associated with an increased risk of osteoporosis, indicating the importance of physical activity on risk reduction of falls through specific muscle strengthening and balancetraining activities, which in turn would preserve muscle strength, delay sarcopenia (age-related muscle loss), and maintain neuromuscular function necessary to keep balance and good reaction to fall. In terms of effects on bone mass, physical activity may stimulate bone formation and thus improve BMD through exposing the skeleton to mechanical strain. In addition, Omland et al., found that physical activity was positively correlated to $\mathrm{BMD}$, and also reported that exercise had a protective role in BMD. ${ }^{56}$

This study failed to find any significant association between smoking and osteoporosis. Consistent with our 
finding, Young et al. also failed to find a significant correlation between smoking and osteoporosis. ${ }^{57}$ On the contrary, Benson and Shulman and Krall and DawsonHughes found a significant association between tobacco exposure and the risk of osteoporosis. ${ }^{58,59}$

A strong association existed between family history of osteoporosis and the risk of developing osteoporosis in our study. Similar to our finding, other studies ${ }^{60-62}$ showed that family history of osteoporosis was a significant and independent risk factor for osteoporosis.

\section{Conclusion}

There is a high prevalence of osteoporosis and osteopenia among Jordanian postmenopausal women. Necessary steps are needed for more public education and wider dissemination of information about osteoporosis and its prevention.

\section{Limitations}

First, our study sample was withdrawn from a pool of Jordanian postmenopausal women referred for DEXA screening during the study period, an approach that carries the risk of selection bias and subsequently, the conclusions may be influenced. However, our exclusion criteria, which eliminated many patients with chronic diseases and others on medications, which may interfere with bone density, minimized this effect to a great extent. Second, although the majority of data were collected from the medical radiological laboratory records performed in the center, an additional confirmatory phone interview was used to gather information on certain variables related to lifestyle behaviors, coffee drinking, exercise, and calcium supplementation, as well as family history of osteoporosis during the first 5 months of 2015, which were beyond the study period, and participants were asked to estimate the average daily consumption of coffee, calcium, and minutes of exercise "during the last year."

\section{Recommendations}

There is a need for further research to intensify public health education to improve women's knowledge and practices regarding osteoporosis and its prevention with special advice on adequate calcium, caffeine, and vitamin $\mathrm{D}$ intakes along with encouragement to do more regular physical activity.

\section{Author Disclosure Statement}

No competing financial interests exist.

\section{References}

1. Johnell O, Kanis JA. An estimate of the world wide prevalence and disability associated with osteoporotic fractures. Osteoporos Int. 2006;17:1726-1733.

2. Kanis JA. WHO Technical Report, University of Sheffield, United Kingdom, p. 66, 2007.

3. Shilbayeh S. Prevalence of osteoporosis and its reproductive risk factors among Jordanian women: a cross-sectional study. Osteoporos Int. 2003;14:929-940.

4. El-Heis MA, Al-Kamil EA, Kheirallah KA, et al. Factors associated with osteoporosis among a sample of Jordanian women referred for investigation for osteoporosis/Facteurs associes a l'osteoporose dans un echantillon de femmes Jordaniennes orientees pour un depistage de I'osteoporose. East Mediterr Health J. 2013;19:459.

5. Chon KS, Sartoris DJ, Brown SA, et al. Alcoholism-associated spinal and femoral bone loss in abstinent male alcoholics, as measured by dual X-ray absorptiometry. Skeletal Radiol. 1992;21:431-436.

6. Jordan KM, Cooper C. Epidemiology of osteoporosis. Best Pract Res Clin Rheumatol. 2002;16:795.

7. Leibson CL, Tosteson AN, Gabriel SE, et al. Mortality, disability, and nursing home use for persons with and without hip fracture: a population-based study. J Am Geriatr Soc. 2002;50:1644-1650.

8. Abushaikha L, Omran S. A survey of osteoporosis risk factors and practices among Jordanian women. J Int Womens Stud. 2013;11:153-161.

9. Wongdee $\mathrm{K}$, Charoenphandhu N. Osteoporosis in diabetes mellitus: possible cellular and molecular mechanisms. World J Diabetes. 2011;2:41-48.

10. Adil C, Aydın T, Taşpınar Ö, et al. Bone mineral density evaluation of patients with type 2 diabetes mellitus. J Phys Ther Sci. 2015;27:179.

11. American Diabetes Association. Standards of medical care in diabetes 2011. DC 2011;30:S4-S40.

12. World Health Organization. Guidelines for Controlling and Monitoring the Tobacco Epidemic. WHO: Geneva, 1998.

13. World Health Organization. Global Recommendations on Physical Activity for Health. WHO: Geneva, 2010.

14. World Health Organization. Physical Status: The Use and Interpretation of Anthropometry: Report of WHO Expert Committee. WHO: Geneva, 1995.

15. International Osteoporosis Foundation (IOF). Sources of Vitamin D, 2008. Available at http://iofbonehealth.org (accessed May 20, 2017).

16. International food information council foundation. IFIC Review, Caffeine and health clarifying the controversies, 2014. Available at www.foodinsight.org/IFIC_Review_Caffeine_and_Health_Clarifying the_Controversies (accessed May 20, 2017).

17. Afifi S, Rahahleh WA, Hadidi KA. Caffeine content in Turkish coffee: A question of concern in sport community. Dirasat: Educational Sciences. 2008;35:730-738

18. Rapuri $P$, Gallagher J, Kinyamu $H$, et al. Caffeine intake increases the rate of bone loss in elderly women and interacts with vitamin $D$ receptor genotypes. Am J Clin Nutr. 2001;74:694-700.

19. World Health Organization. Research on the Menopause in the 1990s: Report of a WHO Scientific Group. WHO: Geneva, 1996.

20. Holick MF. Vitamin D deficiency. N Engl J Med. 2007;357:266-281.

21. Demir B, Haberal A, Geyik P, et al. Identification of the risk factors for osteoporosis among postmenopausal women. Maturitas. 2008;60:253256.

22. Waliullah S, Sharma V, Srivastava R, et al. Prevalence of primary post menopausal osteoporosis at various sites in Indian females. Int J Health Sci Res. 2014;4:113-117.

23. Sadat-Ali M, Al-Habdan IM, Al-Mulhim AA, et al. Bone mineral density among postmenopausal Saudi women. Saudi Med J. 2004;25:1623-1625.

24. Sharif F, Ahmadimoghadam N, Mousavinasab N. The relationship between type 2 diabetes mellitus and bone density in postmenopausal women. Int J Endocrinol Metab. 2006;4:117-122.

25. Anaforoglu I, Nar-Demirer A, Bascil-Tutuncu N, et al. Prevalence of osteoporosis and factors affecting bone mineral density among postmenopausal Turkish women with type 2 diabetes. J Diabetes Complications. 2009;23:12-17.

26. van Daele $\mathrm{PL}$, Stolk RP, Burger $\mathrm{H}$, et al. Bone density in non-insulindependent diabetes mellitus: the Rotterdam Study. Ann Intern Med. $1995 ; 122: 409-414$. 
27. Al-Maatouq MA, El-Desouki MI, Othman SA, et al. Prevalence of osteoporosis among postmenopausal females with diabetes mellitus. Saudi Med J. 2004;25:1423-142.

28. Moghimi N, Rahimi E, Derakhshan S, et al. Osteoporosis in postmenopausal diabetic women; prevalence and related factors. Iranian J Nucl Med. 2008;16:28-33

29. Sharami S, Millani M, Alizadeh A, et al. Risk factors of osteoporosis in women over 50 years of age: a population based study in the North of Iran. J Turkish-German Gynecol Assoc. 2008;9:38-44.

30. D'Amelio P, Spertino E, Martino F, et al. Prevalence of postmenopausal osteoporosis in Italy and validation of decision rules for referring women for bone densitometry. Calcif Tissue Int. 2013;92:437-443.

31. Ito $M$, Yamada M, Hayashi K, et al. Relation of early menarche to high bone mineral density. Calcif Tissue Int. 1995;57:11-14.

32. Parker SE, Troisi R, Wise LA, et al. Menarche, menopause, years of menstruation, and the incidence of osteoporosis: the influence of prenatal exposure to diethylstilbestrol. J Clin Endocrinol Metab. 2013;99:594-601.

33. Gerdhem $\mathrm{P}$, Obrant $\mathrm{KJ}$. Bone mineral density in old age: the influence of age at menarche and menopause. J Bone Min Metab. 2004;22:372-375.

34. Sioka C, Fotopoulos A, Georgiou A, et al. Age at menarche, age at menopause and duration of fertility as risk factors for osteoporosis. Climacteric. 2010;13:63-71.

35. Paganini-Hill A, Atchison KA, Gornbein JA, et al. Menstrual and reproductive factors and fracture risk: the Leisure World Cohort Study. $J$ Womens Health. 2005;14:808-819.

36. Allali F, Maaroufi H, El Aichaoui S, et al. Influence of parity on bone mineral density and peripheral fracture risk in Moroccan postmenopausal women. Maturitas. 2007:57:392-398.

37. Gur A, Nas K, Cevik R, et al. Influence of number of pregnancies on bone mineral density in postmenopausal women of different age groups. J Bone Miner Metab. 2003;21:234-241.

38. Harris SS, Dawson-Hughes B. Weight, body composition, and bone density in postmenopausal women. Calcif Tissue Int. 1996;59:428-432.

39. Pruzansky ME, Turano $M$, Luckey $M$, et al. Low body weight as a risk factor for hip fracture in both black and white women. J Orthop Res. 1989;7:192-197.

40. Zhao LJ, Liu YJ, Liu PY, et al. Relationship of obesity with osteoporosis. J Clin Endocrinol Metab. 2007;92:1640-1646.

41. $\mathrm{Ng} \mathrm{N}$, Kaye EK, Garcia RI. Coffee consumption and periodontal disease in males. J Periodontol. 2014;85:1042-1049.

42. Su SJ, Chang KL, Su SH, et al. Caffeine regulates osteogenic differentiation and mineralization of primary adipose-derived stem cells and a bone marrow stromal cell line. Int J Food Sci Nutr. 2013;64:429-436.

43. Macedo RM, et al. Osteointegration of autogenous bone graft associated with osteoblastic cells under treatment with caffeine. Implant Dent. 2011;20:369-373.

44. Lu P-Z, Lai C-Y, Chan W-H. Caffeine induces cell death via activation of apoptotic signal and inactivation of survival signal in human osteoblasts. Int J Mol Sci. 2008;9:698-718.

45. Liu SH, et al. Caffeine enhances osteoclast differentiation from bone marrow hematopoietic cells and reduces bone mineral density in growing rats. J Orthop Res. 2011;29:954-960.

46. Lacerda SA, Matuoka RI, Macedo RM, et al. Bone quality associated with daily intake of coffee: a biochemical, radiographic and histometric study. Braz Dental J. 2010;21:199-204.

47. Krall EA, Dawson-Hughes B. Heritable and life-style determinants of bone mineral density. J Bone Miner Res. 1993;8:1-9.

48. Ross AC, Taylor CL, Yaktine AL, et al.; Institute of Medicine (US) Committee to Review Dietary Reference Intakes for Vitamin D and Calcium. DRI, Dietary Reference Intakes: Calcium, Vitamin D. National Academies Press (US), Washington, DC, 2011.

49. National Institutes of Health (U.S.). Optimal Calcium Intake. National Institutes of Health, Bethesda; pp. 1-31; 1994.

50. Shea BJ, Adachi JD, Cranney A, et al. Calcium Supplementation on Bone Loss in Postmenopausal Women. The Cochrane Library, 2004.

51. Allain TJ, Dhesi J. Hypovitaminosis D in older adults. Gerontology. 2002;49:273-278.

52. Parfitt AM, Gallagher JC, Heaney RP, et al. Vitamin D and bone health in the elderly. Am J Clin Nutr. 1982;36:1014-1031.
53. Ensrud KE, Duong TU, Cauley JA, et al. Low fractional calcium absorption increases the risk for hip fracture in women with low calcium intake. Ann Intern Med. 2000;132:345-353.

54. Gaugris S, Heaney R, Boonen S, et al. Vitamin D inadequacy among postmenopausal women: a systematic review. QJM. 2005;98:667-676.

55. Mezquita-Raya P, Muñoz-Torres M, De Dios Luna J, et al. Relation between vitamin $D$ insufficiency, bone density, and bone metabolism in healthy postmenopausal women. J Bone Miner Res. 2001;16:1408-1415.

56. Omland LM, Tell GS, Ofjord S, et al. Risk factors for low bone mineral density among a large group of Norwegian women with fractures. Eur J Epidemiol. 2000;16:223-229.

57. Young D, Hopper JL, Nowson CA, et al. Determinants of bone mass in 10 to 26-year-old females: a twin study. J Bone Miner Res. 1995;10:558-567.

58. Benson BW, Shulman JD. Inclusion of tobacco exposure as a predictive factor for decreased bone mineral content. Nicotine Tob Res. 2005;7: 719-724.

59. Krall EA, Dawson-Hughes B. Smoking increases bone loss and decreases intestinal calcium absorption. J Bone Miner Res. 1999;14:215-220.

60. Seeman E, Hopper JL, Bach LA, et al. Reduced bone mass in daughters of women with osteoporosis. N Engl J Med. 1989;320:554-558.

61. Soroko SB, Barrett-Connor E, Edelstein SL, et al. Family history of osteoporosis and bone mineral density at the axial skeleton: the Rancho Bernardo Study. J Bone Miner Res. 1994;9:761-769.

62. Robitaille J, Yoon PW, Moore CA, et al. Prevalence, family history, and prevention of reported osteoporosis in US women. Am J Prev Med. 2008;35:47-54.

Cite this article as: Hyassat D, Alyan T, Jaddou H, Ajlouni KM (2017) Prevalence and risk factors of osteoporosis among Jordanian postmenopausal women attending the National Center for Diabetes, Endocrinology and Genetics in Jordan, BioResearch Open Access 6:1 85-93, DOI: 10.1089/biores.2016.0045.

\begin{tabular}{|c|}
\hline Abbreviations Used \\
\hline $\mathrm{ADA}=$ American Diabetes Association \\
\hline $\mathrm{BMD}=$ bone mineral density \\
\hline $\mathrm{BMI}=$ body mass index \\
\hline DEXA = dual-energy X-ray absorptiometry \\
\hline $\begin{array}{c}\text { NCDEG = National Center for Diabetes, Endocrinology, } \\
\text { and Genetics }\end{array}$ \\
\hline TIDM = type 1 diabetes mellitus \\
\hline
\end{tabular}

